\title{
Interactive Statistics: can we use experience from a large diverse student cohort to provide professional development for a wider population?
}

\author{
Rachel Hilliam* \& Carol Calvert \\ The Open University \\ ${ }^{*}$ Corresponding Author: Rachel.Hilliam@open.ac.uk
}

Keywords: Statistics; Interactive; Career and Professional Development

\begin{abstract}
Statistics pervades everyone's lives, whether it is through media coverage, reading reports, weighing up internal risks or evaluating decisions. Most managers are swamped by endless targets, dashboards and spreadsheets, but few organisations have enough employees with statistical skills to support the requirement for evidence based decision making. The need to equip today's workforce to deal with the increased amount of data is imperative. The shortage of mathematics and statistics teachers is also likely to increase as the Government aims by 2020 to provide all post 16 students with continued mathematical education until the age of 18. At The Open University we have devised a highly successful first level statistics module which is simultaneously studied by students across a range of different disciplines, many of whom encounter statistics at some point in their qualification. This has been achieved by using topics which are of interest to everyone rather than being discipline specific. The module has produced some impressive results particularly when analysing the progress of different cohorts of students, not just from varying disciplines, but also across a broad spectrum of students with differing backgrounds. It is thought that by adapting these techniques it is possible to produce high quality statistics provision to be widely used as professional career development for employees.
\end{abstract}

\section{Introduction}

In 2013 The Open University first produced a statistics module Introducing Statistics (M140) to be studied by students in the first level of their degree. This module was compulsory for students studying Mathematics, Statistics and some qualifications in Economics, Computing and Social Science, but also had to appeal to students across a range of different subjects including Psychology, Criminology, Education, Business and Engineering. In addition the University offers students the opportunity to study for an Open Degree. This qualification requires students to study a set number of credits at every level of their qualification, but subject to any required pre-requisites, the students can choose modules from the majority on offer throughout the entire University. It is well recognised that teaching statistics to students from other disciplines is particularly challenging, often due to a lack of interest in a subject which they may well perceive as mathematical (Gordon, 2004). One of the ways in which interest amongst students can be maintained is to embed the statistics into the discipline which the student is studying, although this was not an option for M140 as it simultaneously had to interest all students across a wide range of disciplines.

Students may study the module starting either in October or February each year with the period of study lasting 9 months in each case. 
Interactive Statistics: can we use experience from a large diverse student cohort to provide professional development for a wider population?

In October 2015, 919 students studied this module; including 247 BSc (Hons) Mathematics, 125 BSc (Hons) Mathematics and Statistics, 76 BSc (Hons) Mathematics and its learning, 74 BSc (Hons) Economics and Mathematical Sciences and 26 BSc (Hons) Computing \& IT with a second subject. In addition there were a number of students taking this module from qualifications without mathematical content such as Business Studies, Business Management, Leadership and Management, Natural Sciences, Environmental Studies, Humanities, Psychology and History. Perhaps notably there were 63 students taking this module as part of their Open Degree and 39 students who were studying this module without linking it to any qualification.

Not only do students on this module study a wide range of qualifications, but their demographics are equally diverse with this particular cohort ranging in age from below 21 to over 65 years of age, with $25 \%$ of the students aged between 30 and 39 . Over $20 \%$ of the students started the module with their highest previous qualification being less than A-level, $55 \%$ of them were in full time work, $17 \%$ in part time work, $19 \%$ not in paid work or unemployed and $3 \%$ retired.

There has been an equally diverse spread of students on this module in every presentation since 2013.

\section{The Introducing Statistics Module (M140)}

The module has been designed to increase the confidence of students, many of whom have not studied statistics before, as many nonmathematics students experience anxieties when learning statistics (Onwuegbuzie \& Wilson, 2003). To reduce the apprehension felt by these students it is usual to ensure the statistics is connected to their area of study (Biggs \& Tang, 2011). However with such a diverse cohort of students, rather than aligning the statistics teaching to any particular discipline, M140 takes the approach of using areas of importance to all people regardless of discipline, employment or background, these being Money, Education and Health. These topics are used to exemplify the ideas and techniques. However the emphasis is on the importance of statistics and statistical thinking. The module consists of eleven units. However each unit title reflects one of the three topic areas rather than the statistical technique covered in each unit (Table 1). By using these three topics the relevance to society is stressed and therefore appeals to all students regardless of subject discipline.

\begin{tabular}{|c|c|c|}
\hline $\begin{array}{c}\text { Example } \\
\text { area }\end{array}$ & Unit title & $\begin{array}{l}\text { Statistics } \\
\text { covered }\end{array}$ \\
\hline \multirow{5}{*}{ Money } & $\begin{array}{l}\text { Looking for } \\
\text { patterns }\end{array}$ & \multirow{5}{*}{$\begin{array}{l}\text { Descriptive } \\
\text { statistics, } \\
\text { sampling } \\
\text { techniques, } \\
\text { regression }\end{array}$} \\
\hline & Prices & \\
\hline & Earnings & \\
\hline & Surveys & \\
\hline & Relationships & \\
\hline \multirow{4}{*}{ Education } & Truancy & \multirow{4}{*}{$\begin{array}{l}\text { Probabilities, } \\
\text { Hypothesis } \\
\text { Tests, } \\
\text { Contingency } \\
\text { Tables, Chi- } \\
\text { square Test, } \\
\text { Confidence } \\
\text { Intervals }\end{array}$} \\
\hline & $\begin{array}{l}\text { Factors } \\
\text { affecting } \\
\text { reading }\end{array}$ & \\
\hline & $\begin{array}{l}\text { Teaching how } \\
\text { to read }\end{array}$ & \\
\hline & $\begin{array}{l}\text { Comparing } \\
\text { schools }\end{array}$ & \\
\hline \multirow[b]{2}{*}{ Health } & Experiments & \multirow{2}{*}{$\begin{array}{l}\text { Practical } \\
\text { Statistical } \\
\text { Investigation, } \\
\text { Clinical Trials, } \\
\text { Bias }\end{array}$} \\
\hline & $\begin{array}{l}\text { Testing new } \\
\text { drugs }\end{array}$ & \\
\hline
\end{tabular}

Table 1 Outline of Topics and Unit Titles for Introducing statistics.

The module content emphases the rationale of the statistical methods, rather than theoretical derivation. Students apply what they have learnt to small data sets by hand and use MINITAB for larger datasets. The fact that random variation exists in data is a strong thread running throughout the module and becomes evident through first-hand experience when they encounter the unit entitled Experiments. In this unit the students have to grow mustard seeds and construct their own dataset consisting of the length of roots. The analysis of this dataset forms part of their assessment for the module, with 
Interactive Statistics: can we use experience from a large diverse student cohort to provide professional development for a wider population?

alternative provision made for students who, due to accessibility, may not be able to perform the experiment.

The material expands on questions of interest based in these three areas and develops ways of collecting and using data to answer realworld questions with an emphasis on the clear communication of conclusions. Many Open University students study whilst working and students frequently comment on the direct application of this module to their workplace.

"I've found myself challenging reports and conclusions in my own work environment as a result of this module."

"I have some previous experience of statistics in the workplace, and was keen to increase my basic foundation in the subject. This was an ideal course with which to start that process. It was appropriately challenging and yet well grounded in reality. Indeed, the subjects chosen to illustrate the various statistical techniques were drawn from contemporary debate and, from my perspective, shone fresh light upon sometimes contentious matters. $A$ genuinely interesting course!"

The need for continual professional training and the move towards degree apprenticeships has motivated us to consider whether the module can be broken down and used in bite size pieces for a wider audience than Open University students. An adaption of one unit of this module is currently available for external use in a freely available website OpenLearn ${ }^{1}$ This resource, entitled Prices, location and spread, is based on the unit 'prices' (Table 1) and covers mean, median, weighted means, upper and lower quartile and then extends these ideas to calculate a simple chained price index using the Retail Prices Index and Consumer Prices Index to measure prices changes. Other units could be adapted in a similar way making them standalone resources for employers to use for professional development or part of an apprenticeship package.

\section{Interactive online resources}

In addition to ensuring the material is delivered through key examples in Money, Education and Health, there is also a strong emphasis on the interactive nature of the material. There has been much evidence to suggest that students benefit greatly from a problem solving method of teaching statistics (Marriott et al, 2009). There are a number of online resources which complement the printed material, including over 70 screencasts which demonstrate key statistical topics (Figure 1).

As in many higher education institutions (Mills, 2002) interactive computer animations illustrate particular concepts (Figure 2). For many students these are key in overcoming barriers to their learning of specific concepts.

These computer animations and screencasts can easily be embedded into standalone material and five such screencasts are freely available in the OpenLearn material.

\section{Continuous assessment with feedlback}

The study pattern is punctuated with computermarked practice quizzes which are designed to test students' understanding and provide graded instantaneous feedback in order to assist with learning. This would make ideal training material for employees since these can be accessed to suit the individual learner's needs. The quizzes combine a rich symbolic question template with a computer algebra package, allowing multiple parallel versions of each quiz to be generated from a bank of questions. Each question provides feedback on incorrect responses and hints to help with answers, whilst always referring the students back to the relevant part of the module material. Students are allowed three attempts at each question and the level of support increases with each attempt (Figures 3-5).

1 http://www.open.edu/openlearn/sciencemaths-technology/prices-location-andspread/content-section-0 


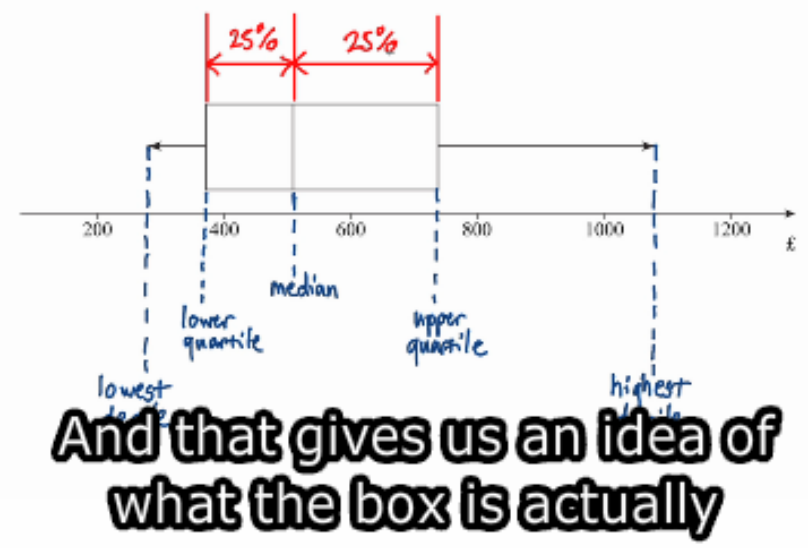

$1101: 52$

$02: 13$

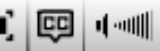

Download Show transcript

$\rightarrow$ Next: Screencast 3: Recognising skewness in a boxplot

Figure 1 Screencast explaining boxplots

Each point on the plot below represents the price of one small television. For televisions with the same price, the corresponding points are stacked on top of each other

You can move the plotted points by moving the blue circles beneath the $x$-axis to the left and right, using your mouse.

Alternatively, select 'Show point labels' and choose a point from the drop-down list. Your chosen point label will be indicated and you can move the relevant point using the left-arrow and right-arrow buttons.

To show the quartiles, standard deviation and range on the plot, click on the relevant tick box for each.

To go back to the starting values, click on 'Reset'.

\begin{tabular}{l|l|} 
Show accessibility help & Show accessibility controls \\
\hline
\end{tabular}

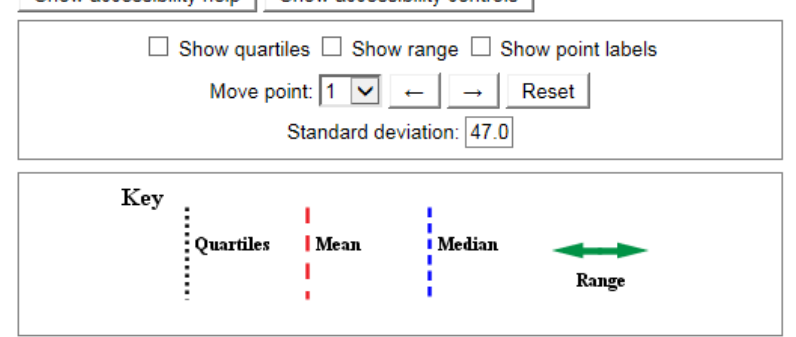

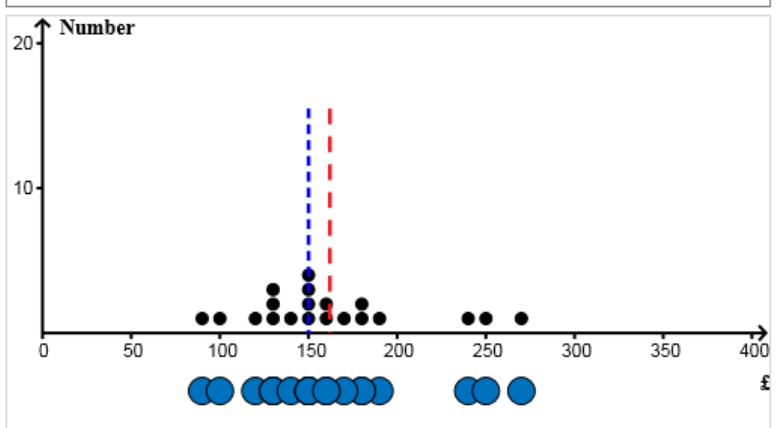

Figure 2 Interactive computer animation to explore sensitivity and resistance 
Interactive Statistics: can we use experience from a large diverse student cohort to provide professional development for a wider population?

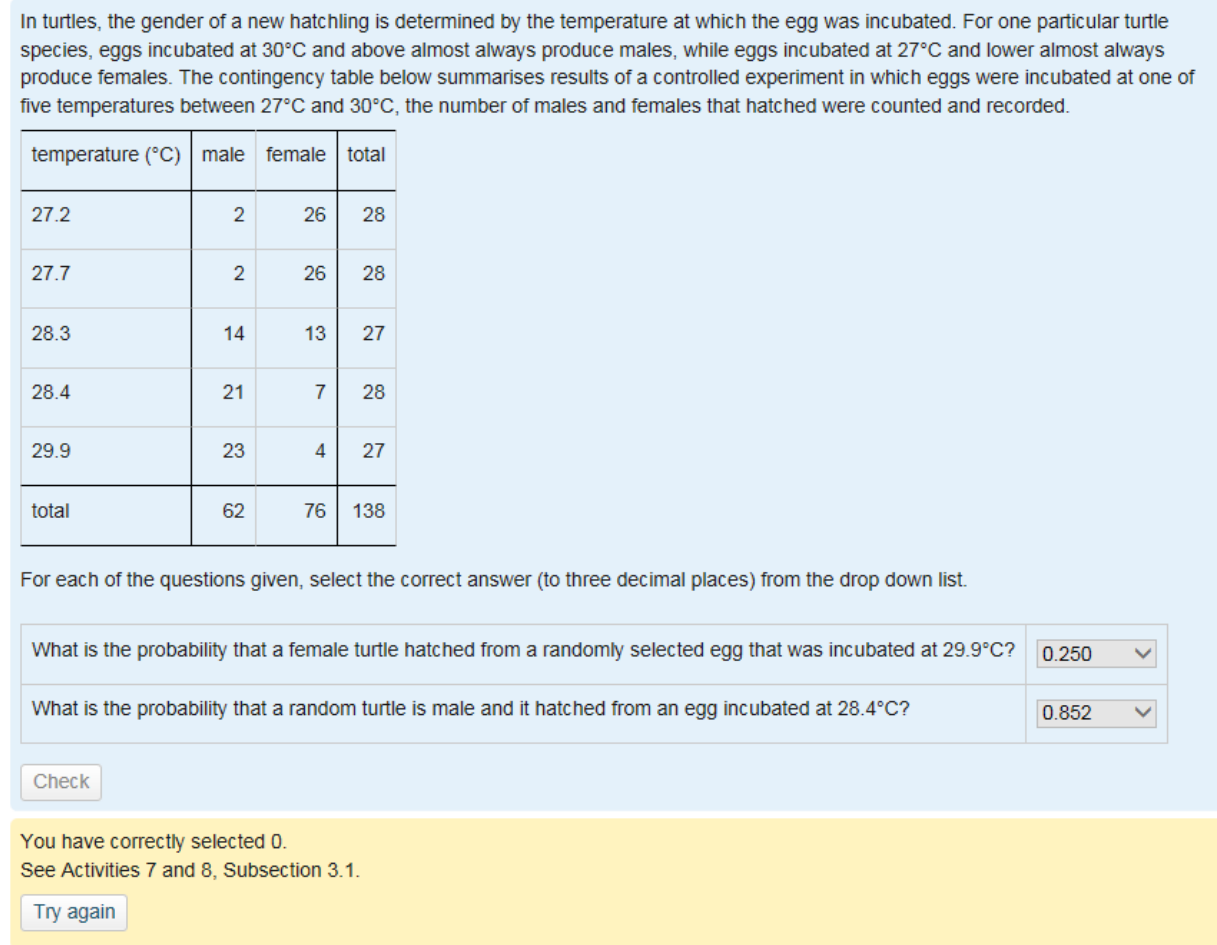

Figure 3 Attempt 1 at a practice quiz question

For each of the questions given, select the correct answer (to three decimal places) from the drop down list.
What is the probability that a female turtle hatched from a randomly selected egg that was incubated at $29.9^{\circ} \mathrm{C}$ ?
What is the probability that a random turtle is male and it hatched from an egg incubated at $28.4^{\circ} \mathrm{C}$ ?
Check
You have correctly selected 0 .
The joint probability of two events, $A$ and $B$, denoted $\mathrm{P}(A$ and $B$ ) is the probability that $A$ and $B$ occur together. In contrast, the
conditional probability of $A$ given $B$, denoted $\mathrm{P}(A \mid B)$, is the probability that $A$ occurs given that $B$ occurs.
See Activities 7 and 8 , Subsection 3.1.
Try again

Figure 4 Attempt 2 at a practice quiz question (image cropped to show answers and feedback only)

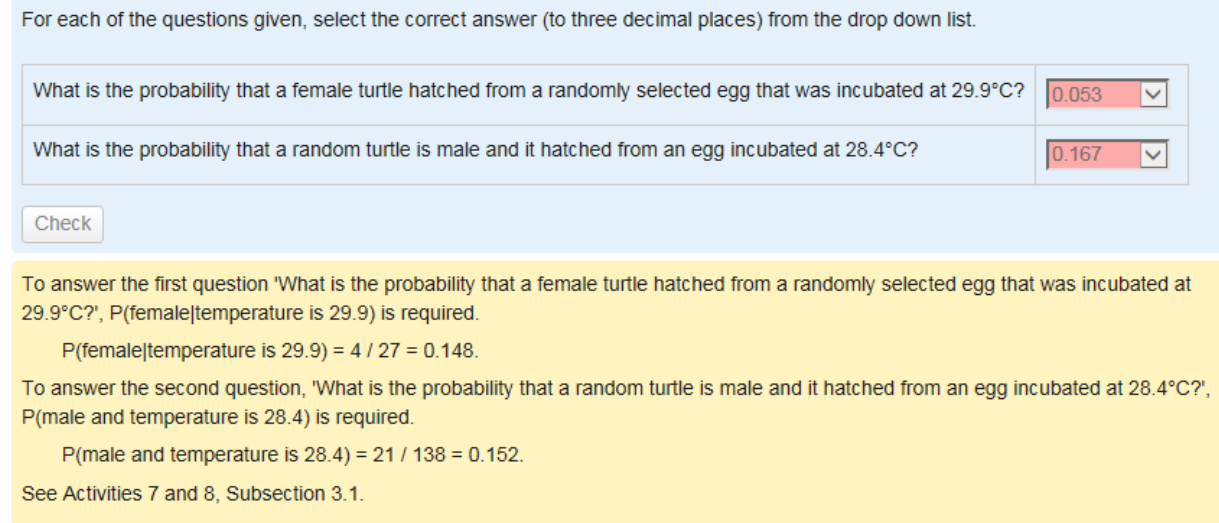

Figure 5 Attempt 3 at a practice quiz question (image cropped to show answers and feedback only) 
Interactive Statistics: can we use experience from a large diverse student cohort to provide professional development for a wider population?

\section{Summary}

Since the first presentation in 2013 over 4000 students have passed this module. By learning from the experience of delivering a module to students from a wide variety of backgrounds and subject disciplines through the use of real life examples of interest to all people (in this case Money, Education and Health), it is possible to see how this same idea could be used by employers who need to upskill their workforce in statistics. It is clear from comments in end of module surveys that students who study this module as part of a non-mathematical qualification find the subject and way of presenting the material valuable, particularly when they are able to relate the techniques to their own place of work. The module has even made students reconsider their study goals and has made others appreciate the importance of statistics in the workplace and everyday life. This may be of particular interest to teachers who find themselves needing to deliver mathematics and statistics when their subject specialism lies elsewhere.

"I wasn't sure what to expect of this course, I was interested in the statistics as much to see what statistics was all about. Certainly an eye-opener!! Most people tend to think that politicians, news and advertising media come up with figures to back up what they want to come across in their spiel, so you tend to ignore stats figures as just figures that generally are thrown about. Well, now I know that this is not strictly true, there are good statistics that are very definitely necessary and helpful and interesting. I do know that statistics are used in every walk of life, you need them."

The module is written in such a way as to be engaging to all students including those with a prior mathematics and statistics phobia. This is also true of many people who find themselves in the workplace needing to engage with statistics. This may be of particular importance if, as a society, we are to meet the apprenticeship agenda, since statistics will need to feature in many of these offerings.

"As a student at school, I used to hate statistics. I studied S1 at A-Level and decided to go no further than that, because statistics seemed like a horrible side of mathematics to me. However, upon starting to study this module, I found myself intrigued by statistics. ... The way that the information is presented to the student portrays statistics as an intriguing science, giving examples of how it is used in real-life situations. After seeing how useful statistics actually is to society in practice, I have definitely changed my mind about the science. Thank you to the creators of M140!"

Whilst many of the techniques used in this module are specifically designed to support students studying as distance learners, many of these methods can, and are, being employed by other HEl providers. It is hoped that the module will be relevant for statistical training within organisations, of use to teachers and help to address the current shortage of specialist mathematics teachers, whilst also contributing to the apprenticeship models now being delivered. The biggest strength of this module is the ability to deliver statistics simultaneously and at scale, to such a diverse and large student population, through a single module using examples of interest to the whole of society; money, education and health. This model is not only useful for large service teaching courses, but a potential model for delivering career and professional development in statistics and analytical methods to a wider population.

\section{References}

Biggs, J. \& Tang, C. (2011). Teaching for quality learning at University. Berkshire: McGraw-Hill.

Gordon, S. (2004). Understanding student's experiences of statistics in a service course. Statistics Education Research Journal, 6(2), 35-46.

Marriott, J., Davies, N. \& Gibson, L. (2009). Teaching, Learning and Assessing Statistical Problem Solving. Journal of Statistics Education, 17(1).

McConway, K. (2016) Prices, location and spread, http://www.open.edu/openlearn/sciencemaths-technology/prices-location-andspread/content-section-0 
Interactive Statistics: can we use experience from a large diverse student cohort to provide professional development for a wider population?

Mills, J. (2002). Using Computer Simulation Methods to Teach Statistics: A Review of the Literature. Journal of Statistics Education, 10(1).

Onwuegbuzie, A. \& Wilson, V. (2003).

Statistics anxiety: Mature, etiology, antecedents, effects, and treatments - a comprehensive review of the literature. Teaching in Higher Education, 8(2), 195-209.

The Open University (2013) M140 Introducing Statistics, Milton Keynes, The Open University. 